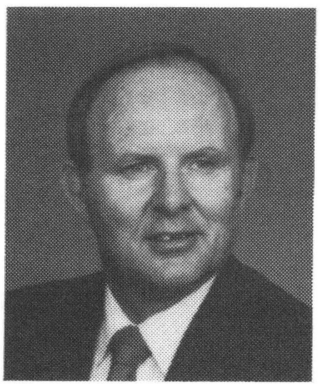

Editorial

Jack D. Gaskill, Editor

More on "Idea-Type" Papers

I have received more reader response regarding the recommendation that "idea-type" papers be published in Optical Engineering (see my editorials in the November 1987 and March 1988 issues). I will attempt to condense this response-some of which was for and some of which was against-in the paragraphs below.

Dan Awtrey wrote that history has often shown it to be more important that an idea merely be put forth for consideration than that it be presented in a fully developed and documented form. He pointed out that Alexander Graham Bell had an idea that communication could be achieved with light but that this notion remained little more than a curiosity until the advent of optical fibers. It would appear that Dan thinks Bell's idea was important in the development of optical communications even though that idea was not proffered in a "fully developed and documented" form.

Dan also noted that ideas and concepts that may be at first ignored, scorned, or laughed at, often turn out to be of considerable importance at a later time. Consequently, he applauded Joe Geary's recommendation that "idea-type" papers be accepted by the journal, but he also agreed with Bud VanderLugt's prediction that many more of these kinds of papers would be submitted than could be reviewed or printed. Dan concluded by suggesting that, instead of accepting all such papers for publication, only those directed toward specific subjects according to an established schedule would be considered. I'm not certain how the subjects or schedule would be determined, but it is an interesting idea.

Bill Wolfe wrote to express his opposition to the publication of "idea-type" papers in Optical Engineering. He stated that SPIE already has an appropriate mechanism for idea papers-the symposia. He agrees with Bud that an archival journal should not be cluttered with ideas that have not been subjected to significant testing. The symposia, however, provide a forum for the discussion of such ideas on the spot, and they also are recorded in the associated proceedings, which, although unrefereed, have the fresh, undistilled essence of whatever was presented (almost). Bill concluded by encouraging us to keep the journal archival and the symposia freewheeling!

Stay tuned-there may be more to come.

\section{Future Special Issue Call for Papers}

January 1989

\section{Optical Computing}

\section{Guest Editors}

Profassor Sing H. Lee

Electrical and Computer Engineering

University of California, San Diego

La Jolla, CA 92093

619/534-2413

Dr. Ravindra A. Athale

BDM Corporation

7915 Jones Branch Drive

McLean, VA 22102-3396

703/848-7556

The January 1989 special issue of Optical Engineering will be devoted to optical computing. Topics to be covered will include materials, devices, architectures, and algorithms for optical computing, advances in organic materials, ferroelectric liquid crystals and multiple quantum well structures for optical computing devices, computer-generated holograms and photorefractive crystals for optical interconnections, 3-D optical memory, optics for artificial intelligence, optical neural computing, and programmable architectures and systems for digital optical computing. Authors are encouraged to submit manuscripts for consideration on any of the above or related topics to the Guest Editors before June 15, 1988. 